\title{
Reinventando a Educação Infantil em tempos de Covid-19: as medidas pedagógicas implementadas no município de Guarulhos/SP
}

\author{
Reinventing Early Childhood Education in Covid-19 times: the pedagogical \\ measures implemented in the city of Guarulhos / SP
}

\author{
Luciana Longuini da Silva \\ Pós-graduada em Gestão Escolar pela Universidade de São Paulo \\ Vice-diretora de uma escola de Educação Infantil da Rede Municipal de Guarulhos. \\ Guarulhos, São Paulo - Brasil. \\ luvicediretora@gmail.com \\ Kellen Jacobsen Follador \\ Doutora em História \\ Universidade de São Paulo - USP. \\ São Paulo, São Paulo - Brasil. \\ kellenjf@usp.br
}

Resumo: Com a chegada da pandemia da Covid-19, a rotina de pais, crianças e professores precisou se adequar à nova realidade. Sem a possibilidade dos encontros presenciais na sala de aula, as instituições de ensino passaram a recorrer às atividades a distância para dar seguimento ao ano letivo. Diante desse cenário de isolamento social, a Prefeitura Municipal de Guarulhos passou a oferecer atividades pedagógicas por meio do Programa Saberes em Casa, em parceria com a TV Câmara. Este artigo busca apresentar as etapas para a implementação do programa como recurso didático na Rede Municipal de Ensino entre os meses de março a junho de 2020 e as alternativas da equipe gestora de uma escola de Educação Infantil para atender as crianças durante a suspensão das aulas presenciais.

Palavras-chave: Educação a distância. Programa saberes em casa. Educação infantil.

Abstract: After COVID-19 outbreak, the routine of parents, children and teachers needed to adapt to the new reality. Without the possibility of face-to-face meetings in the classroom, educational institutions started to use e-learning to continue the school year. Given this scenario of social isolation, the municipality of Guarulhos started offering educational activities through the Saberes em Casa Program, in partnership with TV Câmara. This paper aims to present the steps for the implementation of the program as a didactic resource in the Municipal Education System between March and June 2020 and the alternatives of the management team of an early childhood school to assist children during the suspension of face-to-face classes.

Keywords: e-learning. Saberes em casa program. Early childhood education. 
SILVA, Luciana Longuini da; FOLLADOR, Kellen Jacobsen. Reinventando a Educação Infantil em tempos de Covid-19: as medidas pedagógicas implementadas no município de Guarulhos/SP

\section{Introdução}

Todos tivemos nossas rotinas radicalmente modificadas a partir do surgimento da Covid19, fato que impôs um excepcional desafio às autoridades mundiais na execução de ações de combate para conter a altíssima capacidade de transmissão do vírus.

A postura adotada pela Secretaria Municipal de Educação (SME) do município de Guarulhos no decorrer do ano de 2020 buscou atender as necessidades deste período atípico sem perder de vista a trajetória, o compromisso e a valorização da história guarulhense no que se refere à concepção de educação da Rede Municipal.

O município tem sua Proposta Curricular Quadro de Saberes Necessários (QSN) como sinalizadora de que não podemos abrir mão do direito a uma educação humanizadora, emancipatória e de qualidade. Esta proposta curricular está pautada em documentos normativos como a Lei de Diretrizes e Bases da Educação Nacional (LDB- lei no 9394), de 1996, as Diretrizes Curriculares Nacionais para a Educação Infantil (BRASIL, DCNEI), de 2010 e a Base Nacional Comum Curricular (BRASIL, BNCC), de 2017. Foi escrita e discutida com educadores que atuam na Rede Municipal de Guarulhos, com o objetivo de nortear a construção dos currículos nas escolas e todas as ações e atividades desenvolvidas com as crianças.

Os responsáveis pela SME têm o objetivo de favorecer o processo educativo dos educandos da Rede Municipal e, dessa forma, contribuir para sua aprendizagem e desenvolvimento, até que de fato aconteça o retorno presencial às escolas, apesar de ainda não haver uma data prevista. Desse modo, este trabalho tem como objetivos gerais apresentar a implementação do Programa Saberes em Casa (modalidade EaD) como recurso didático e o papel do gestor escolar como apoio para a implementação de medidas pedagógicas na Rede Municipal de Ensino de Guarulhos entre os meses de março a junho, período no qual a pesquisa foi desenvolvida.

Neste cenário, visando o alcance do maior número de educandos possível, as atividades passaram a ser disponibilizadas por meio do Canal Câmara de TV, assim como pelo Portal da Secretaria de Educação e pelo canal do Youtube. O Programa de TV Saberes em Casa está sendo gravado pelos profissionais do Departamento de Orientações Educacionais e Pedagógicas, com apoio dos professores das classes bilíngues do município e dos professores de música da orquestra de Guarulhos. As temáticas do Programa estão sendo elaboradas por grupo de educadores da Rede, em conjunto com o referido departamento.

A proposta da Prefeitura de Guarulhos em investir na EaD como modalidade de ensino é válida e condizente com a defesa que a professora da Faculdade de Educação da Universidade de São Paulo (USP) Carlota Boto (2020) faz da educação nesse momento de pandemia. Essa 
pesquisadora demonstra preocupação com os alunos das escolas públicas e das universidades que não têm acesso à internet banda larga, o que faz parecer inviabilizada a mobilização dos recursos da internet para dar sequência ao ensino, correndo o risco de favorecer a segregação social, considerada inadmissível por ela e pela SME de Guarulhos. A autora ressalta a necessidade de reinvenção da educação e da escola, valendo-se de novas plataformas e novas estratégias com ponderação na decisão e urgência na ação.

Nesse sentido, os gestores das escolas municipais passaram a analisar alternativas adequadas à realidade social e econômica de cada escola, considerando também as diferentes características familiares presentes em cada comunidade escolar. A interação entre as escolas e o Departamento de Orientações Educacionais e Pedagógicas, por meio de diferentes canais de comunicação, possibilitou a socialização de iniciativas desenvolvidas pelas escolas para estabelecer a integração de suas ações.

A interação entre as escolas e da escola como instituição e seus/suas educadores/as é muito importante para que possam explicitar o compromisso e a solidariedade com a comunidade escolar, desenvolvendo formas de contato, abordando conjuntos temáticos que reconheçam o estado de exceção, promovendo análises de suas características e possíveis consequências e buscando estratégias de manutenção das interações, sem amplificar o cenário de desigualdade no acesso ao conhecimento escolar (ANGELUCCI, 2020).

Destacamos que além dos objetivos gerais anteriormente citados, esta pesquisa também buscou apresentar as ações que estão sendo implementadas pela Rede Municipal de Guarulhos, relacionadas às medidas de proteção para enfrentamento da emergência de saúde pública decorrente da Covid-19 e descrever as alternativas da equipe gestora de uma escola de Educação Infantil da prefeitura de Guarulhos, para atender as crianças durante a suspensão das aulas presenciais, de modo que elas possam, mesmo mediante a distância física, ter acesso às atividades que contribuam com seu processo educativo, utilizando, para isso, os meios de comunicação existentes e que estejam ao alcance do maior número possível de crianças.

\section{As medidas tomadas pela Prefeitura de Guarulhos nas primeiras semanas de pandemia}

A presente pesquisa apresenta um estudo de cunho qualitativo e teve como base uma revisão sistemática de documentos públicos e um estudo de caso.

Os arquivos públicos são geralmente volumosos e organizados segundo ordens de classificação e, apesar do caráter público, nem sempre estão acessíveis. São exemplos de arquivos públicos: os arquivos governamentais (federais, regionais, escolares ou municipais), os do estado 
civil, assim como alguns arquivos jurídicos. Os documentos públicos não arquivados incluem revistas, jornais, periódicos, anúncios, circulares, boletins, que possuem um caráter de distribuição (CELLARD, 2008).

Ao surgirem as primeiras notícias sobre a pandemia no estado de São Paulo, a Secretaria Municipal de Educação de Guarulhos passou a editar decretos e outros instrumentos legais e normativos para que os gestores tomassem providências em relação ao enfrentamento da emergência de saúde pública. Esses documentos foram enviados ao e-mail das unidades escolares, da equipe gestora e publicados no portal da SE, de forma que pudessem ser acessados pela comunidade escolar.

A leitura dos memorandos circulares e decretos no site da SE permitiu identificar o caminho e o planejamento para construção dessa atividade. Com base nas leituras foram definidas as seguintes etapas e descrição das atividades (Tabela 1).

Tabela 1 - Etapas da pesquisa documental

\begin{tabular}{l|l} 
Etapas & Descrição \\
\hline Pré-análise & $\begin{array}{l}\text { Definição dos objetivos e fontes a serem utilizadas } \\
\text { Quais perguntas pretende-se responder a partir da } \\
\text { análise dos dados }\end{array}$ \\
\hline Exploração do Material & $\begin{array}{l}\text { Formulação de hipóteses } \\
\text { Organização e classificação dos documentos } \\
\text { conforme categorias }\end{array}$ \\
\hline Análise & Fichas documentais \\
\hline
\end{tabular}

Fonte: Elaborada pelas autoras.

No Diário Oficial do município foram publicados os seguintes decretos emitidos pelo Departamento de Relações Administrativas e promulgados pelo prefeito Gustavo Henric Costa (Tabela 2): 
SILVA, Luciana Longuini da; FOLLADOR, Kellen Jacobsen. Reinventando a Educação Infantil em tempos de Covid-19: as medidas pedagógicas implementadas no município de Guarulhos/SP

Tabela 2 - Decretos municipais

\begin{tabular}{|c|c|c|}
\hline Decreto & Data & Assunto \\
\hline 36711 & $16 / 03 / 2020$ & $\begin{array}{l}\text { Situação de emergência em decorrência da Covid-19. Abertura das } \\
\text { escolas entre os dias } 16 \text { e } 20 / 03 \text { para ações de conscientização e } \\
\text { orientações sobre a gradativa redução do atendimento aos alunos }\end{array}$ \\
\hline 36723 & $17 / 03 / 2020$ & $\begin{array}{l}\text { Dispensa de servidores portadores de doenças crônicas, servidores } \\
\text { com mais de } 60 \text { (sessenta) anos, gestantes e lactantes a partir de } \\
\text { 18/03/2020. Suspensão das aulas presenciais de } 23 \text { a } 31 / 03 / 2020 \text {. } \\
\text { Antecipação do recesso escolar previsto para julho para o período de } \\
1 \text { a } 30 \text { de abril de } 2020\end{array}$ \\
\hline 36753 & $20 / 03 / 2020$ & $\begin{array}{l}\text { Prestação de serviços por meio do regime de teletrabalho, trabalho a } \\
\text { distância ou de forma remota, a todos os servidores e estagiários, } \\
\text { quando a função assim lhes permitir e disponibilizar canais } \\
\text { telefônicos ou eletrônicos de acesso aos interessados, como } \\
\text { alternativa para evitar ou reduzir a necessidade de comparecimento } \\
\text { pessoal nas unidades de atendimento }\end{array}$ \\
\hline 36757 & $23 / 03 / 2020$ & $\begin{array}{l}\text { Declara o Estado de Calamidade Pública no município de Guarulhos. } \\
\text { Todos os servidores públicos ficam autorizados, quando a função } \\
\text { assim lhes permitir, exercer suas atribuições fora das instalações } \\
\text { físicas do (s) respectivo (s) órgão (s) de lotação, em trabalho a } \\
\text { distância - trabalho remoto - regime bome office - teletrabalho, } \\
\text { mediante a utilização de tecnologia de informação e de comunicação, } \\
\text { quando disponíveis }\end{array}$ \\
\hline 36810 & $17 / 04 / 2020$ & $\begin{array}{l}\text { Prorrogando até } 10 \text { de maio de } 2020 \text { os prazos estabelecidos nos } \\
\text { decretos municipais no } 36723 \text { de } 17 / 03 / 2020 \text { e } 37753 \text { de } \\
20 / 03 / 2020\end{array}$ \\
\hline 36832 & $01 / 05 / 2020$ & $\begin{array}{l}\text { Suspensão das atividades escolares presenciais no período de } 04 \text { a } \\
29 / 05 / 2020\end{array}$ \\
\hline
\end{tabular}

Fonte: Diário Oficial do município de Guarulhos

Em concordância com os Decretos Municipais, a SME, por meio de seus departamentos passou a encaminhar memorandos aos diretores das escolas com orientações para a implementação de suas ações (Tabela 3). 
Tabela 3 - Memorandos enviados aos diretores das escolas da Prefeitura de Guarulhos

\begin{tabular}{|c|c|c|}
\hline Memorando & Data & Assunto \\
\hline $01 / 2020$ & $16 / 03 / 2020$ & $\begin{array}{l}\text { Abertura das escolas no período entre os } \\
\text { dias } 16 \text { e } 20 / 03 \text { para a realização de ações de } \\
\text { conscientização dos familiares, informando sobre } \\
\text { a suspensão das aulas a partir do dia } 23 / 03 / 2020 \\
\text { e sobre a antecipação do recesso escolar entre } \\
01 / 04 / 2020 \text { e } 30 / 04 / 2020\end{array}$ \\
\hline $10 / 2020$ & $24 / 04 / 2020$ & $\begin{array}{l}\text { Suspensão, no período de } 04 \text { a } 29 \text { de } \\
\text { maio de } 2020 \text {, das atividades escolares realizadas } \\
\text { de forma presencial nas escolas da Rede } \\
\text { Municipal de Ensino e sobre a disponibilização } \\
\text { de videoaulas, a partir de } 04 \text { de maio de } 2020 \text {, } \\
\text { por meio do Programa Saberes em Casa } \\
\text { Guarulhos. Os funcionários (diretores de escola, } \\
\text { vice-diretores, professores, professores } \\
\text { coordenadores pedagógicos, supervisores } \\
\text { escolares, assistentes de gestão, agentes escolares } \\
\text { e cozinheiros, inclusive aqueles considerados } \\
\text { integrantes do grupo de risco), passaram a } \\
\text { realizar a prestação de serviços em regime de } \\
\text { teletrabalho, conforme dispõe a portaria } \\
\text { 680/2020, cumprindo formação obrigatória. }\end{array}$ \\
\hline $37 / 2020$ & $24 / 04 / 2020$ & $\begin{array}{l}\text { Orientação sobre a formação obrigatória } \\
\text { para todos os educadores como elemento } \\
\text { constitutivo da jornada de trabalho ou em } \\
\text { complemento a ela. A formação ocorre por meio } \\
\text { do AVA (Ambiente Virtual de Aprendizagem no } \\
\text { endereço http:// curriculo.guarulhos.sp.gov.br, o } \\
\text { qual passou a ser acessado por todos a partir do } \\
\text { dia 04/05/2020, tendo como foco o estudo da } \\
\text { Proposta Curricular QSN/2019. }\end{array}$ \\
\hline $04 / 2020$ & $29 / 04 / 2020$ & $\begin{array}{l}\text { Orientação sobre o atendimento e formas } \\
\text { de trabalho nas unidades escolares. Para diretores } \\
\text { de escola, vice-diretores, professores, professores } \\
\text { coordenadores pedagógicos, assistentes de gestão } \\
\text { escolar e professores reabilitados, a presença é } \\
\text { registrada por meio das plataformas de } \\
\text { formação/ AVA, das atividades de atendimento } \\
\text { em regime de teletrabalho, bem como } \\
\text { presencialmente, quando necessário, } \\
\text { correspondendo a um dia de trabalho, ou seja, } \\
\text { todos nesta condição garantem meia presença } \\
\text { referente à disponibilidade para o } \\
\text { teletrabalho/presencial e a outra metade da } \\
\text { jornada é computada por meio das plataformas } \\
\text { de formação/AVA. }\end{array}$ \\
\hline
\end{tabular}




\begin{tabular}{|l|l|l|}
\hline Memorando & \multicolumn{1}{|l|}{ Data } & \multicolumn{1}{|c|}{$\begin{array}{c}\text { Assunto } \\
\text { Garantia da autonomia para que sejam } \\
\text { propiciadas atividades remotas a todos os alunos } \\
\text { matriculados na rede própria e parceira. Além } \\
\text { das atividades oferecidas pelo Programa Saberes } \\
\text { em Casa, a equipe gestora da escola tem } \\
\text { autonomia para elaborar atividades próprias, de } \\
\text { iniciativa de cada unidade escolar, sempre em } \\
\text { consonância com a proposta curricular (QSN) e } \\
\text { considerada a realidade familiar, social e } \\
\text { econômica dos alunos. }\end{array}$} \\
\hline $20 / 2020$ & $07 / 05 / 2020$ \\
\hline \multirow{2}{*}{$29 / 05 / 2020$} & $\begin{array}{l}\text { Plano de acompanhamento pedagógico } \\
\text { durante o isolamento social, no qual devem ser } \\
\text { registradas as ações que já estão sendo realizadas } \\
\text { pela equipe escolar, bem como propostas e novas } \\
\text { ações para o mês de junho que se fizerem } \\
\text { necessárias, em consonância com a Proposta } \\
\text { Curricular -Quadro de Saberes } \\
\text { Necessários/QSN (2019) e o Programa Saberes } \\
\text { em Casa. }\end{array}$ \\
\hline
\end{tabular}

Fonte: Secretaria de Educação da Prefeitura de Guarulhos.

As equipes de todas as escolas da rede própria e instituições parceiras, por meio da modalidade de trabalho remoto, passaram a se dedicar ao planejamento de ações pedagógicas que visam à integração curricular com o Programa Saberes em Casa, oferecido pela SME.

Para auxiliar os professores no planejamento das atividades, a SME publicou a revista Sugestão de criação e utilização de Ambientes Virtuais de Interação (AVIs) entre educadores (as) e educandos (as). Impressa e de circulação restrita aos profissionais da educação do município, a revista apresenta recursos audiovisuais que podem facilitar a interação na modalidade EaD. A revista também apresenta indicação e orientações sobre o uso de plataformas de comunicação para a realização de reuniões virtuais, para o compartilhamento de atividades e outras possibilidades.

Diante das possibilidades de educação remota incentivadas e oferecidas pela SME, os gestores escolares passaram a investigar as necessidades de sua comunidade escolar a fim de identificar quais crianças têm condições de usufruir da EaD disponibilizada pela prefeitura, principalmente por meio do Programa Saberes em Casa (TV) e de outras formas com conexão à internet. 
SILVA, Luciana Longuini da; FOLLADOR, Kellen Jacobsen. Reinventando a Educação Infantil em tempos de Covid-19: as medidas pedagógicas implementadas no município de Guarulhos/SP

\section{O Programa Saberes em Casa: o uso da TV, da internet e das redes sociais como modalidade EaD}

\section{A proposta educativa do Programa Saberes em Casa}

Diante da impossibilidade de retorno com segurança às atividades presenciais, a equipe pedagógica da SME de Guarulhos, reuniu-se durante todo o mês de abril por meio de plataformas digitais, para analisar alternativas que permitissem o acesso de todas crianças da Rede Municipal a atividades que contribuíssem com a construção dos saberes expressos em sua Proposta Curricular, denominada Quadro de Saberes Necessários (QSN).

Deste modo, há de se pensar em outros meios de comunicação que facilitem o diálogo entre a criança e sua instituição de ensino. Dentre estes meios, a TV surge como tecnologia acessível financeiramente e largamente difundida entre a população. Como citado por Becker (2005), na maioria dos casos, a televisão é a única fonte de informação e de cidadania do brasileiro.

Portanto, após longo período de reflexão, a equipe chegou à conclusão que devido às desigualdades digitais existentes no município, a tecnologia mais acessível seria a TV, o que levou a prefeitura a estabelecer uma parceria com a TV Câmara para a exibição do Programa Saberes em Casa.

O Programa Saberes em Casa passou a ser transmitido diariamente, de segunda a sexta, a partir de 4 de maio de 2020, das 9h às 10h30min, pela TV RS 21, canal 58.1 da TV aberta e na TV Câmara no canal 7 (Net/Claro). Ao término de cada edição, no período da tarde, as atividades ficam disponíveis no Portal da SME, que pode ser acessado por meio do endereço eletrônico: http://portaleducacao.guarulhos.sp.gov.br/siseduc/.

No Portal da Educação, além de todos os programas exibidos na TV, são disponibilizados conteúdos inéditos e complementares. Aos materiais produzidos internamente são acrescidos desenhos animados e documentários de curta duração por meio de parceria com Canal Futura, Fundação Roberto Marinho, Pinguim Produções e Canal Manual do Mundo, livros no formato PDF para baixar gratuitamente e jogos online. Além disso, com a orientação da família, as crianças também podem postar nas redes sociais as atividades que foram realizadas utilizando a hashtag \#Saberesemcasa.

As atividades disponíveis no Portal da Educação são complementares, não sendo obrigatório o acesso ou a realização. São possibilidades que têm como objetivo complementar e ampliar o conhecimento de mundo da criança que poderá acompanhar as atividades pela TV e realizá-las em seu próprio caderno, para compartilhá-las com os professores e demais colegas no 
SILVA, Luciana Longuini da; FOLLADOR, Kellen Jacobsen. Reinventando a Educação Infantil em tempos de Covid-19: as medidas pedagógicas implementadas no município de Guarulhos/SP

retorno às aulas presenciais. Cabe destacar que os professores estão acompanhando as atividades e as aprendizagens que são desencadeadas para que sejam retomadas posteriormente.

O Programa Saberes em Casa foi planejado com características interdisciplinares, ou seja, podemos ter um tema como ponto de partida, como por exemplo, um tema relacionado às aprendizagens em Natureza e Sociedade (Ciências, História e Geografia) e, a partir dele, propor atividades em Língua Portuguesa e Matemática.

Fazenda (2011) ressalta que somente uma "atitude interdisciplinar" possibilita avançar no processo de construção de uma prática contextualizada na qual as ciências se interpenetrem proporcionando novas compreensões da realidade. Outra autora que reflete sobre o assunto é Lück (2003). Para ela, a interdisciplinaridade é o processo que envolve a integração e o engajamento de educadores, num trabalho conjunto de interação das disciplinas do currículo escolar com a realidade. Essa interação tem condições de superar a fragmentação do ensino, objetivando a formação integral das crianças, a fim de que possam exercer criticamente a cidadania, mediante uma visão global de mundo, e serem capazes de enfrentar os problemas complexos, amplos e globais da realidade atual.

A interdisciplinaridade também está presente nas aulas e atividades de alfabetização, que são voltadas para quem ainda não sabe ler e escrever de forma convencional, independente da sua idade ou turma. As crianças, jovens e adultos que desenvolveram aprendizagens sobre a leitura e a escrita, realizam as atividades de pesquisa e resolução de situações-problema de matemática, de acordo com os conhecimentos já estabelecidos.

No Programa Saberes em Casa estão sendo propostas atividades para todos os educandos, da Educação Infantil ao Ensino Fundamental e EJA, de modo a garantir os saberes necessários para cada um de acordo com suas potencialidades.

Além do programa exibido na TV Câmara, os educandos podem acessar o Portal da Educação onde encontram o espaço "Saberes em Casa" no endereço: http://portaleducacao.guarulhos.sp.gov.br/siseduc/portal/site/listar/categoria/11/. Acessando esse espaço os educandos encontram as seguintes atividades:

- Saberes em Casa - ficam disponíveis os programas do Canal da TV para que possam assistir, caso não consigam fazê-lo no horário aberto, ou ainda, assistir quantas vezes desejar.

- Dá um Play - Neste espaço podem ser encontrados links de acesso para canais do Youtube que podem acrescentar conteúdos e propostas para seus estudos. 
SILVA, Luciana Longuini da; FOLLADOR, Kellen Jacobsen. Reinventando a Educação Infantil em tempos de Covid-19: as medidas pedagógicas implementadas no município de Guarulhos/SP

- Minha Biblioteca - A cada semana, são disponibilizados livros que podem ser lidos online ou baixados para leitura no celular ou computador.

- Vamos Brincar - Neste espaço, são disponibilizados jogos educativos que podem ser baixados.

- Desafio do dia - são postados nesse espaço todos os desafios apresentados no Programa Saberes em Casa. Assim, o aluno pode relembrar o desafio de uma aula sem precisar assisti-la novamente

- Dica do Professor - os professores da Rede Municipal gravam vídeos com dicas sobre diferentes assuntos que são abordados nas videoaulas do Programa Saberes em Casa. Desse modo, os alunos podem assistir a esses vídeos e, inclusive, rever seus professores.

- Educação Infantil - Nessa seção, voltada especialmente à Educação Infantil, são disponibilizados roteiros de estudos, links para vídeos e os desafios "Quebrando a cuca”.

As atividades são planejadas de forma que possam ser desenvolvidas pelos educandos com certa autonomia. Analisando o Programa Saberes em Casa como um meio de suprir as necessidades educacionais de jovens e adultos em fase de alfabetização, concordamos com Paulo Freire (1996) para quem a autonomia - dentre elas a educacional - é uma condição humana do indivíduo que se reconhece como ser histórico e que é capaz de compreender e transformar a sua realidade.

O Programa Saberes em Casa conta ainda com uma programação diária, na qual em cada dia leva ao ar uma atividade diferente dedicada a diferentes áreas do conhecimento (Tabela 4), pois um currículo que leve em consideração a diversidade deve ser, antes de tudo, flexível e passível de adaptações, sem perda de conteúdo. Além disso, deve ser desenhado tendo como objetivo geral a redução de barreiras atitudinais e conceituais, e se pautar em uma ressignificação do processo de aprendizagem na sua relação com o desenvolvimento humano (OLIVEIRA; MACHADO, 2007). 
Tabela 4 - Programação diária

\begin{tabular}{|l|l|l|}
\hline DIA & ATIVIDADE & OBJETIVO \\
\hline Segunda-feira & LIBRAS em Casa & $\begin{array}{l}\text { Atividade dedicada especialmente aos alunos surdos } \\
\text { da Rede, porém todos poderão aproveitar a } \\
\text { oportunidade e aprender esta língua }\end{array}$ \\
\hline Terça-feira & $\begin{array}{l}\text { Desenvolvimento } \\
\text { da autonomia nas } \\
\text { AVDs }\end{array}$ & $\begin{array}{l}\text { As AVDs (Atividades de Vida Diária) podem ser } \\
\text { feitas por todos, mas esta atividade é pensada para as } \\
\text { crianças com deficiência, sendo necessária a }\end{array}$ \\
\hline Quarta-feira & $\begin{array}{l}\text { Programa Música } \\
\text { nas Escolas }\end{array}$ & $\begin{array}{l}\text { Conhecer elementos musicais importantes para } \\
\text { aprender a tocar um instrumento musical e entender } \\
\text { como a música favorece a aprendizagem }\end{array}$ \\
\hline Quinta-feira & $\begin{array}{l}\text { Arte com } \\
\text { Experiência e } \\
\text { Educação Física } \\
\text { É hora de Inglês }\end{array}$ & $\begin{array}{l}\text { Nesta atividade, trabalha-se com o desenvolvimento } \\
\text { da criatividade e com o movimento do corpo }\end{array}$ \\
\hline Sexta-feira & $\begin{array}{l}\text { Trabalha-se como a Cultura e a Língua Inglesa } \\
\text { presentes em nosso dia a dia }\end{array}$ \\
\hline
\end{tabular}

Fonte: Secretaria de Educação da Prefeitura de Guarulhos.

Até aqui foram apresentadas as medidas tomadas pela prefeitura de Guarulhos nas primeiras semanas de pandemia quanto à situação da educação no município, e, nesse contexto, a rápida iniciativa de prosseguir com o ano letivo na modalidade EaD por meio do Programa Saberes em Casa. Desde o início, a SME favoreceu e incentivou o diálogo democrático acerca do programa junto aos gestores escolares. Estes puderam apurar as necessidades de sua comunidade escolar para saber quais alunos teriam ou não condições de usufruir da nova modalidade de ensino disponibilizada pela prefeitura, principalmente por meio do Programa Saberes em Casa (TV, site, redes socais) e de outras formas com conexão à internet.

Assim, nas páginas seguintes serão apresentadas, a critério de relato de caso, as adaptações que uma escola municipal precisou realizar para adequar a modalidade $\mathrm{EaD}$ à realidade de sua comunidade escolar.

\section{A gestão escolar e a implementação democrática do Programa Saberes em Casa: um relato de caso}

A escola estudada possui atualmente 297 alunos com idade entre 4 e 5 anos, matriculados nos Estágios I e II da Educação Infantil/ Pré-escola. Atende nos períodos da manhã e da tarde, 
das $7 \mathrm{~h}$ às $18 \mathrm{~h}$ e conta com 25 funcionários (uma diretora, uma vice-diretora, uma professora coordenadora pedagógica, um assistente de gestão, uma agente escolar, dez professoras, três cozinheiras, quatro controladores de acesso e três auxiliares de serviços gerais).

Ainda em meados de março, quando a prefeitura decretou situação de emergência em decorrência da Covid-19, as escolas mantiveram-se abertas para ações de conscientização e orientações sobre a gradativa redução do atendimento aos alunos. Painéis com orientações sobre os canais de comunicação existentes na escola foram fixados nos portões e em locais de grande movimentação da comunidade escolar.

Após a SME optar por não delimitar a utilização de apenas uma ferramenta tecnológica, devido ao fato de cada unidade educacional ter sua realidade e necessidades, deixando a critério das equipes escolares decidirem quais ferramentas tecnológicas preferiam utilizar, a equipe da unidade escolar optou por baixar o aplicativo WhatsApp Business. Esse aplicativo foi instalado no celular de uma das gestoras, na intenção de apoiar as famílias e de organizar momentos de trocas de práticas pedagógicas, propostas de atividades, ações e brincadeiras que fossem interessantes para o desenvolvimento e a aprendizagem dos alunos.

A utilização do WhatsApp possibilitou a aproximação e o diálogo da escola com a comunidade escolar, permitindo o planejamento da continuidade das ações educacionais, não apenas sob o ponto de vista administrativo e pedagógico, mas, humano, considerando o cenário atual e a realidade que aos poucos era exposta pelos pais em suas mensagens.

Muitas vezes a família atribui somente à escola a tarefa de educar seus filhos e diante das atuais necessidades das crianças são necessárias novas alternativas para melhorar a relação entre família e escola, e promover consequentemente ganhos no processo de aprendizagem dos alunos. Assim, a escola deve utilizar todas as oportunidades de contato com os pais, para passar informações relevantes sobre seus objetivos, recursos, problemas e também sobre as questões pedagógicas. Só assim, a família poderá se sentir comprometida com a melhoria da qualidade escolar e com o desenvolvimento de seu filho como ser humano (PARO, 2000). Nesse sentido, os gestores devem criar mecanismos que possibilitem a vinda dos pais para dentro da escola - mesmo que virtualmente -, favorecendo a sua participação efetiva nas ações da escola (WERNECK, 2001).

Estabelecida a comunicação com os pais, a escola, diante da autonomia garantida pela SME, precisava pensar em atividades remotas para complementar as atividades do Programa Saberes em Casa. Desse modo, gestores e professores passaram a realizar reuniões pedagógicas de forma remota. A primeira reunião, por videoconferência, ocorreu no dia 11 maio 2020 por meio da ferramenta Zoom meeting. 
SILVA, Luciana Longuini da; FOLLADOR, Kellen Jacobsen. Reinventando a Educação Infantil em tempos de Covid-19: as medidas pedagógicas implementadas no município de Guarulhos/SP

A professora coordenadora pedagógica orientou as educadoras a assistirem o Programa Saberes em Casa e a acompanharem as atividades do Portal da Educação diariamente para que possa ser dada continuidade ao conteúdo apresentado após apreciação das atividades realizadas pelos educandos (Desafio do Dia) no retorno presencial. As professoras foram orientadas a priorizarem a ludicidade, criatividade, recreação e interação ao prepararem atividades remotas para as crianças da Educação Infantil, evitando retrocessos cognitivos, corporais e/ou socioemocionais.

O lúdico é parte integrante do mundo infantil e da vida de todo ser humano, e inclusive no processo de ensino e aprendizagem o mesmo não deve ser visto apenas como diversão (MALAQUIAS; RIBEIRO, 2013). As brincadeiras e os jogos são imprescindíveis no desenvolvimento da criança, tornando-se atividades adequadas no processo de ensino e na aprendizagem significativa dos conteúdos curriculares, possibilitando o exercício da concentração, da atenção e da produção do conhecimento (SILVA, 2012).

Por meio de uma aula lúdica, a criança é estimulada a desenvolver sua criatividade e não a produtividade, sendo sujeito do processo pedagógico (KISHIMOTO, 1996). Considerando a criança como sujeito do processo pedagógico, Belloni (2002), destaca que o papel do professor no processo de educação a distância é atuar como mediador do aprendizado, buscando romper a barreira da distância física que o separa do aluno. Nesse sentido, a ludicidade tende a aproximar professor e aluno mesmo na modalidade EaD.

Apesar do Programa Saberes em Casa ter uma proposta interdisciplinar e contemplar várias etapas da educação, diante da falta de perspectiva para o retorno às aulas presenciais a unidade escolar sentiu a necessidade de manter as crianças em um ritmo de estudo e uma rotina escolar mesmo estando distantes do espaço físico da escola.

Barbosa (2006) considera a rotina como uma categoria pedagógica estruturada pelos profissionais da Educação Infantil para o desenvolvimento do seu trabalho diário. A autora ressalta a importância de compreender a rotina como um dos aspectos que compõem a vida cotidiana, tendo em vista sua complexidade, bem como sua amplitude. Para Coutinho (2002), a boa utilização do tempo será refletida no desenvolvimento das crianças, portanto entende-se que a rotina planejada deve fazer parte do planejamento de cada instituição.

Nas reuniões de planejamento, que passaram a ser semanais, através do Zoom, a equipe passou a preparar atividades que pudessem ser encaminhadas via WhatsApp, sempre acompanhando a temática trazida pelo Programa Saberes em Casa. Além do link do programa encaminhado diariamente aos celulares dos familiares, os mesmos passaram a receber links educativos com músicas, histórias, jogos e brincadeiras. 
Conforme os pais davam a devolutiva sobre a execução das atividades com as crianças, a equipe gestora concluiu que dos 297 alunos, apenas 240 estavam registrados nos contatos do telefone, recebendo diariamente as informações da escola. Motivada pelo compromisso de atender todas as crianças da escola e baseada na Proposta Curricular QSN (2019), a equipe de professores, juntamente com a coordenadora pedagógica, passou a preparar kits de atividades, adequados à faixa etária das crianças e em consonância com as atividades oferecidas pelo Programa Saberes em Casa. Essas atividades são impressas e entregues aos familiares nas datas que eles comparecem à unidade escolar para a retirada do leite em pó e das cestas básicas. Os familiares também são orientados quanto à realização das atividades com as crianças.

Para que a SME possa acompanhar o trabalho desenvolvido pela escola, a coordenadora pedagógica encaminha mensalmente à supervisora escolar um plano de acompanhamento pedagógico, no qual são registradas as ações que já estão sendo realizadas pela equipe escolar, bem como propostas e novas ações para os próximos meses que se fizerem necessárias, em consonância com a Proposta Curricular - Quadro de Saberes Necessários/QSN (2019) - e o Programa Saberes em Casa.

\section{Considerações finais}

Mesmo apresentando uma proposta de uso da EaD na modalidade TV e plataforma digital, nem todas as famílias têm a possibilidade de usufruir dessas ferramentas, dado o contexto social no qual elas estão inseridas. Por isso, por mais que a prefeitura de Guarulhos tenha se adiantado na proposta $\mathrm{EaD} / \mathrm{TV}$, não foi possível alcançar a todos como evidenciado no relato de caso da escola de Educação Infantil.

Ao observar que uma significativa parcela das crianças ficaria desassistida, a escola mencionada procurou buscar meios de atender aquelas que não possuem acesso às tecnologias digitais.

O momento de exceção no qual vivemos impôs à escola de Educação Infantil estudada mudanças na metodologia de ensino adotada até então, evidenciando que o aparato tecnológico pode e deve ser utilizado como mais um recurso, mas os métodos tradicionais não podem ser substituídos em sua totalidade.

A incorporação das novas tecnologias tornou-se um desafio para os professores e funcionários da referida escola. Alguns apresentaram muitas dificuldades, dada sua formação insuficiente e falta de recursos tecnológicos, o que levou as gestoras a explorarem as potencialidades 
pedagógicas das novas tecnologias em reuniões coletivas, possibilitando o compartilhamento de saberes entre a equipe e maior segurança na utilização dos recursos para o planejamento das aulas.

No instante em que os gestores e os educadores, como representantes da classe educadora, identificaram os problemas de ordem social que estavam ligados direta ou indiretamente à escola estabecelaram uma parceria com as famílias, que passaram a ser as grandes protagonistas no processo de ensino e aprendizagem das crianças, revelando que educação se faz com amor e com participação mútua.

Esperamos que os gestores escolares continuem exercendo sua importante missão na mediação entre os educadores e os familiares, sensibilizando os pais na continuidade do protagonismo mesmo após a normalização deste cenário pandêmico e de isolamento social. A parceria da familia com a escola é fundamental para o sucesso da educação e para que pais e filhos vivenciem intensamente os desafios do aprender e do ensinar.

\section{Referências}

ANGELUCCI, B. Muito além das tarefas a cumprir: notas da FEUSP sobre a educação em tempos de isolamento. Faculdade de Educaşão da USP, São Paulo, 2020. Disponível em: http://www4.fe.usp.br/educacao-isolamento/textos. Acesso em 29 de maio de 2020.

BARBOSA, M. C. S. Por amor e por força: rotinas na Educação Infantil. Porto Alegre: Artmed, 2006.

BECKER, V; MONTEZ, C. TV Digital Interativa: Conceitos, Desafios e Perspectivas para o Brasil. Ribeirão Preto: Ed. I2TV, 2004.

BELLONI, M. L. Ensaio sobre educação à distância no Brasil. Revista Educação e Sociedade, ano XXIII, no78, 2002. Disponível em: www.scielo.br. Acesso em 05 de abril de 2020.

BOTO.C. 2020. A educação e a escola em tempos de coronavírus. Jornal da USP. Universidade de São Paulo, São Paulo, SP, Brasil. Disponível em: https://jornal.usp.br/artigos/a-educacao-e-aescola-em-tempos-de-coronavirus/ Acesso em 10 abri. 2020.

BRASIL. 2020. Decreto n. 36711, de 16 de março de 2020. Situação de emergência em decorrencia do COVID-19. Disponível em: https://www.guarulhos.sp.gov.br/diario-oficial/. Acesso em 18 mar 2020.

BRASIL. 2020. Decreto n. 36723, de 17 de março de 2020. Dispensa de servidores portadores de doenças crônicas. Disponível em: https://www.guarulhos.sp.gov.br/diario-oficial/. Acesso em 18 mar 2020.

BRASIL. 2020. Decreto n. 36753, de 20 de março de 2020. Prestação de serviços por meio de teletrabalho. Disponível em: https://www.guarulhos.sp.gov.br/diario-oficial/. Acesso em 21 mar 2020 . 
SILVA, Luciana Longuini da; FOLLADOR, Kellen Jacobsen. Reinventando a Educação Infantil em tempos de Covid-19: as medidas pedagógicas implementadas no município de Guarulhos/SP

BRASIL. 2020. Decreto n. 36757, de 23 de março de 2020. Declara estado de calamidade pública no municipio de Guarulhos. Disponível em: https://www.guarulhos.sp.gov.br/diario-oficial/. Acesso em 01 abr 2020.

BRASIL. 2020. Decreto n. 36810, de 17 de abril de 2020. Prorroga até 10 de maio de 2020 os prazos estabelecidos nos decretos municipais n. 36723 e 37753. Disponível em: https://www.guarulhos.sp.gov.br/diario-oficial/. Acesso em 25 abr 2020.

BRASIL. 2020. Decreto n. 36832, de 01 de maio de 2020. Supensão das atividades escolares presenciais no período de 04 a 29 de maio de 2020 Disponível em:

https://www.guarulhos.sp.gov.br/diario-oficial/. Acesso em 10 mai 2020.

CELLARD, A. A análise documental. In: POUPART, J. et al. (Orgs.). A pesquisa qualitativa: enfoques epistemológicos e metodológicos. Vozes: Petrópolis, 2008.

COUTINHO, A. M. S. As Crianças no interior da creche: a educação e o cuidado nos momentos de sono, higiene e alimentação. Dissertação de Mestrado. Universidade Federal de Santa Catarina. Santa Catarina, 2002.

FAZENDA, I. C. A. Integração e interdisciplinaridade no ensino brasileiro: efetividade ou ideologia. 6 ed. São Paulo: Edições Loyola, 2011 [1979].

FREIRE, P. Pedagogia da autonomia: saberes necessários à prática educativa. 15 ed. São Paulo: Paz e Terra, 1996.

GUARULHOS (SP). Proposta Curricular: Quadro de Saberes Necessários (QSN). Secretaria de Educação de Guarulhos, 2019.

KISHIMOTO, T. M. Jogo, brinquedo, brincadeira e a educação.7 ed. São Paulo: Cortez, 1996.

LÜCK, H. Pedagogia interdisciplinar: fundamentos teórico-metodológicos. 11 ed. Petrópolis: Vozes, 2003.

MALAQUIAS, S.M; RIBEIRO, S.S. A importância do lúdico no processo de ensino- aprendizagem no desenvolvimento da infância. 2013. Disponível em: https://psicologado.com/atuacao/psicologiaescolar/a-importancia-do-ludico-no-processo-de-ensino-aprendizagem-no-desenvolvimento-dainfancia. Acesso em 20 de março de 2020.

OLIVEIRA, E.; MACHADO, K. S. Adaptações curriculares: caminho para uma Educação Inclusiva. In: GLAT, R. (Org.). Educação Inclusiva: Cultura e Cotidiano Escolar. Rio de Janeiro: 7 Letras, 2007.

PARO, V. H. Qualidade do ensino: a contribuição dos pais. São Paulo: Xamã, 2000.

PIAGET, J. O Juízo Moral na Criança. 4 ed. São Paulo: Summus, 1994.

ROUSSEAU, J. J. E. Da Educação. 3 ed. Rio de Janeiro: Bertrand Brasil, 1995.

Recebido em: 30 set. 2020/ Aprovado em: 01 dez. 2020 


\section{Dialogia}

SILVA, Luciana Longuini da; FOLLADOR, Kellen Jacobsen. Reinventando a Educação Infantil em tempos de Covid-19: as medidas pedagógicas implementadas no município de Guarulhos/SP

\section{Cite como}

\section{(ABNT NBR 6023:2018)}

SILVA, Luciana Longuini da; FOLLADOR, Kellen Jacobsen. Reinventando a Educação Infantil em tempos de Covid-19: as medidas pedagógicas implementadas no município de Guarulhos/SP. Dialogia, São Paulo, n. 36, p. 235-251, set./dez. 2020. Disponível em: https://doi.org/10.5585/dialogia.n36.18335.

\section{American Psychological Association (APA)}

Silva, L. L., \& Follador, K. J. (2020, set./dez.). Reinventando a Educação Infantil em tempos de Covid-19: as medidas pedagógicas implementadas no município de Guarulhos/SP. Dialogia, São Paulo, 36, p. 235-251. https://doi.org/10.5585/dialogia.n36.18335. 